\title{
PERSISTENCE OF PRIMITIVE REFLEXES AND ASSOCIATED PROBLEMS IN CHILDREN
}

\begin{abstract}
During the development of the fetus a series of reflexes called primitive reflexes are formed which are involuntary, stereotyped, first and dominant forms of movements during intrauterine life and the first year after birth. Reflexes are of great importance for survival and development, caused by external stimuli and controlled by the brainstem and nervous system, such as messages that are quickly transmitted from the brainstem to the muscles to perform a specific function. At the beginning they are necessary for the nutrition, survival, protection of the new-born, and later in life they are important for the process of learning, communication, emotions, motivation.

In typical development, primary reflexes are naturally inhibited in particular order during the first year; they are displaced by substitutional reflexes called postural reflexes. Postural reflexes are more mature models of motor responses that coordinate balance, coordination and senso-motor development. Retained primitive reflexes can cause developmental delays that are associated with disorders such as ADHD, autism, learning difficulties, cerebral palsy, dyslexia, dystonia, behaviour disorders and sensory processing disorders.

Routine testing of primitive reflexes helps determine the causes of disharmonic development, behavioural problems or learning difficulties, and the use of the reflex integration methods leads to a significant improvement of the condition.
\end{abstract}

Keywords: PRIMITIVE REFLEXES, INTEGRATION, PERSISTENCE, MORO REFLEX, ASYMMETRIC TONIC NECK REFLEX, SPINAL GALANT REFLEX

\section{Introduction}

During the last 4 months of the prenatal life and the first 4 months after delivery, the human movement repertoire includes reflex movements that are involuntary, stereotyped responses to certain stimulations. The baby is born with over than 70 instinctive reflexes, and many of them appear subcortical, more precisely originate from the regions below the brain cortex level, indicating that the reflex movements occurred without direct involvement of the higher brain centres (Чичевска Јованова, Рашиќ Цаневска, 2013; Payne, Isaacs, 2012). 
Primitive reflexes help the brain development. The movements define the schemes of neuronal networks and myelination of the neuronal pathways that allow connection of the different brain regions which will later be important for the learning process, behaviour, communication and emotions. Primitive reflexes play a developmental role, preparing the neonate to move against gravity, gradually leading to voluntary movement by the process of integration during the first months of life. Mature responses in a child's psychomotor progress can only occur if the central nervous system itself has reached maturity. The process consists of the transition from a brain stem reflex response to a cortically controlled response. The process is actually transition from brainstem reflexes to the cortical controlled responses (Goddard, 2002).

When the most sophisticated brain centres begin to develop, primitive reflexes become an obstacle and need to be integrated. The integration means inhibition or transformation of the reflex by the higher centres of neuronal control, so that the pattern of responses is no longer stereotypical. The integration of primitive reflexes leads to the development of the postural reflexes, which are controlled by the middle brain and should remain present during hole our lives. The postural reflexes aim to help the baby deal with the requirements of the environment based on gravity and provide the basis for controlling balance, behaviour and voluntary movement (Goddard, 2014; Fiorentino, 1980).

Although the time of appearance and disappearance of the reflexes in children is various, knowledge of the normal frame for the reflex occurrence and loss is of a particular importance. Most of the primitive reflexes should be integrated during the first year of life, but if the baby fails to inhibit primitive reflexes in appropriate time, his motor development will delay same as the brain development (Blomberg and Dempsey, 2011). Their persistence is proof for the structural abnormalities or immaturity of the central nervous system, and is often found in a combination with the absent or insufficient developed postural reflexes. Early form of infantile movements are significant for assessment of the neuronal maturity of the new-born and greater deviation from the normal time frame indicates the existence of the neuronal immaturity and dysfunction (Malina, Bouchard, Bar-Or, 2004).

There are many factors causing unintegration of the primitive reflexes, but most prevalent are (Goddard, 2017): caesarean, brain damage during the labour, prematurity and low birth weight, shock or big stress during the pregnancy, illness during the first year of live, substance/alcohol/toxic material abuse during the pregnancy, insufficient stimulation and tummy positioning, which helps the development of neck and shoulders muscles, lack of the time spent in free movements on the floor, stressful environment, inappropriate food. The reflexes integrated during the childhood can be activated again as a result of trauma, stress or injury. 
The primitive reflexes can be divided in three groups - multisensory reflex, primitive reflexes of positioning and primitive tactile reflexes. Because of the huge number of reflexes, we will mention some of them.

Multisensory reflex - Moro reflex, the only one of the primitive reflexes that can be triggered by all senses: positioning of the head (vestibular), tactile, visual, audible, olfactory and movement factors, such as baby kicking or sneezing. It is an involuntary reaction to a treat. Sudden movements of the head in the vertical plane, or movements of the head back and forth, cause the appearance of this reflex. The reaction is fast extension of the limbs, deep inhalation, followed by the limb contraction and cry. This is perfectly normal reaction from about 9 weeks after the conception to about 12 weeks after birth, presents a reaction of potential threat and occurs as a result of the nerve/muscle stimulation and the release of the stress hormones adrenaline and cortisol. If this reflex reaction maintains longer than the normal period for inhibition, the persons are constantly exposed to the higher concentrateons of the stress hormones, hypersensitivity can be seen, inappropriate reaction to small treats, hard focusing on objects, and they more prefer peripheral seeing than the central seeing area and have problem in the small detail discrimination. The same effect can impact the hearing, these persons have difficulties in concentration to the verbal messages by ignoring the background noises (Walker, 2013). Other symptoms related to the retained Moro reflex are: mood swings, sudden changes in the behaviour (aggressive and impulsive), visual problems, learning difficulties in reading/writing, strong light hypersensitivity, panic attacks, depression, attention deficits, texture hypersensitivity, ADHD, Asperger syndrome, autistic behaviour, emotional and social immaturity, coordination and balance problems. The instinctive reactions to stimuli cause problems in the long-term memory. Retained Moro reflex is often case in persons with intellectual disability without motor impairment, including people with Down syndrome, athetoid cerebral palsy, and sometime in persons with spastic cerebral palsy (Чичевска Јованова, Рашиќ Цаневска, 2013; Iiyama, Miyajima, Hoshika, 2002).

Spinal Galant reflex appear around the 20 gestational week and should be inhibited around the sixth month after the birth. It is tested when the child is laying on the stomach or when holding down the face. In the new-born, stroking the low back on one side of the spine will result in side flexion of the lumbar (low back) spine away from that side, with raising of the hip on the same side, stimulation of the both sides of the spine simultaneously upward from the pelvis to the neck causes flexion of the limbs, extension of the head and urination (Mejashki-Boshnjak, 2008). This reflex helps the baby develop its vestibular system and along with the asymmetric tonic neck reflex helps the baby in the process of birth, it also contributes to the development of the range of movements of the hips needed for crawling and walking. Persistence of the gallant reflex can cause hypersensitivity to 
the waist area (denial labels and wearing belt), the child will not be able to sit still, constantly turn from side to side and cannot stand still in one position. As a result of the previous symptoms can be noticed attention and concentration problems, enuresis nocturne, scoliosis (if the reflex remained only on the one side of the body), hyperactivity (especially if it wears tight upper clothing or with the back touches the back of stool), postural problems, slow and irregular development of speech, grammar and spelling, problems in walking and performing complex leg activities (Integrated Learning Strategies, 2016).

Primitive reflex of positioning - Asymmetric tonic neck reflex (ATNR) is initiated when the head is turn to the left or right on a horizontal plane. It is activated by the labyrinth in the inner ear and the reaction consists of extension of the limbs at the same side where the face faces, and flexion of the limbs on the opposite side. The eyes are also controlled by this reflex; they are directed toward the extended arm. It appears approximately 18 weeks after gestation, this is a period when the mother becomes aware of the baby movements in the uterus. The baby uses ATNR for its repositioning in the uterus, as a reaction to the changed position of the mother. ATNR should be present at birth; it should help the baby to cross the birth channel. This reflex usually integrates at the age of 6 months. The asymmetric tonic neck reflex is responsible for the development of the muscle tone of the baby, hemisphere domination of the brain, binocular sight, listening with both ears, development of eye-hand coordination (Walker, 2013). A child with retained ATNR may manifest one or more problems. It is always forced to follow the scheme of this reflex, which can be frustrating for the child and to impact its complete physical development. In these children can be noticed that they are not able to roll or to crawl military, because retained ATNR prevents rotation of the head and flexion of the same side of the body. Retained ATNR results in homolog movement - both hands are used together to pull the body forward, and the legs can only be pulled out together or symmetrically. The balance is also affected - when the child is standing he will feel unstable and uncertain, unless his head stands steady in the centre line. The difficulty to cross the middle line causes various problems, the child may manifest problems when manipulating objects with both hands, while reading or writing, the child may not develop dominant lateralization. They also may present difficulties in visual perception, such as symmetrical presentation of figures or symbols on the paper, poor visiomotor integration, eye-hand coordination, which will affect his reading and writing. Because of the previously mentioned problems in reading and writing, retained ATNR is also associated with dyslexia. When this reflex is not integrated can affect also the binocular seeing and the child has reduced ability to see with both eyes in the same time, almost always manifests strabismus. These problems often lead to poor reading skills, inability to follow the line, inability for reading if 
there are many rows on the page, writing difficulties, very strong grip, bad balance and coordination in walking, running, driving rollers, mirror writing of letters and numbers, poor depth perception, eating disorders (Goddard, 2014).

Symmetric tonic neck reflex (STNR) is reflex that is difficult to categorize. In fact, it is not real primitive reflex because it is not present at birth, nor is it a postural reflex because it should not be retained during life, it is positioning reflex and the last ones appears. It appears between the $6^{\text {th }}$ and the $9^{\text {th }}$ month and should disappear until the $11^{\text {th }}$ month, it is stimulated with the flexion and extension of the head, and causes response dividing the body on two halves (from the waist upward and from the waist down), thus two opposite patterns of movements occur on the upper and lower half of the body. When the chin is raised, the arms extend and the legs flexed and vice versa will come when the chin is lowered down. Signs of an retained STWR is a late occurrence or no occurrence of crawling, improper holding of the body, sloping shoulders, bent knees, flexion in the hips, monkey walking - the right hand moves forward with the right leg and vice versa, walking on the fingers, constant swaying and movement when sitting, tends to rely on the table when sitting on a chair due to the decreased muscle tone, especially the spinal muscles, attention and concentration problems, reading problems, writing difficulties, poor memory, clumsiness, and so on (Walker, 2013).

\section{Methodology of the research}

The goal of the research was determination of the persistence of primitive reflexes in preschool children, period of most intensive development. The study included 60 children aged 3-5 years, 30 girls, 10 of whom were 3 years old, eight were 4 years old and twelve were 5 years old. There were also 30 males, six on the age of 3 years, eleven at age of 4 and thirteen at age of 5. For the examination of the primitive reflexes Sally Goddard test was used, and were assessed Moro reflex, palmar reflex, plantar reflex, seeking reflex, spinal gallant reflex, tonic labyrinth reflex, asymmetric tonic neck reflex and symmetric tonic neck reflex. In 3 years old children tests for the tonic labyrinth reflex were harder to use, so we changed with the test proposed by the Integrated Learning Strategies, from Utah, USA. The scoring was adapted to our needs and standards, 0 was meaning that here is no presence of the reflex, 1 was meaning easy reaction of the reflex stimulation and 2 was meaning retained reflex. Each reflex was examined up to 5 times if we noticed presence of the reflex in the child or the response was ambiguous, in order to obtain best positive answers. 


\section{Result analysis and discussion}

In the table number 1 there are results from the examination of the Moro reflex in 3 preschool groups. According the data this reflex is integrated in $93,4 \%$ of male examinees, only two respondents, one 3 years old and one 4 years old, had small - easy reflex reaction. Complete persistence of the reflex was not noticed in any male respondent. In the female group there was not observed any reactions of the reflex. Konicarova and Bob (2012) in their study, where they examined persistence of the primitive reflexes in 20 children with ADHD and 20 children in control group, determinate that there is significantly greater retention of the Moro reflex and spinal gallant reflex in children with ADHD, categorized according the DSM10 (hyperactive behaviour).

Table 1. Analysis of the appearance of Moro reflex

\begin{tabular}{|c|c|c|c|c|c|c|c|c|c|c|}
\hline \multirow[t]{2}{*}{ Reflex } & \multirow[t]{2}{*}{ Gender } & \multirow[t]{2}{*}{ Age } & \multicolumn{2}{|c|}{0} & \multicolumn{2}{|c|}{1} & \multicolumn{2}{|c|}{2} & \multicolumn{2}{|c|}{ Total } \\
\hline & & & $\mathrm{N}$ & $\%$ & $\mathrm{~N}$ & $\%$ & $\mathrm{~N}$ & $\%$ & $\begin{array}{l}\mathrm{N} /+ \\
\text { ans. }\end{array}$ & $\%$ \\
\hline \multirow{6}{*}{ Moro } & \multirow{3}{*}{ Male } & 3 & 4 & 80 & 1 & 20 & 0 & 0 & \multirow[t]{3}{*}{2} & \multirow[t]{3}{*}{93.4} \\
\hline & & 4 & 10 & 91 & 1 & 9 & 0 & 0 & & \\
\hline & & 5 & 12 & 100 & 0 & 0 & 0 & 0 & & \\
\hline & \multirow{3}{*}{ Female } & 3 & 10 & 100 & 0 & 0 & 0 & 0 & \multirow[t]{3}{*}{0} & \multirow[t]{3}{*}{0} \\
\hline & & 4 & 8 & 100 & 0 & 0 & 0 & 0 & & \\
\hline & & 5 & 11 & 100 & 0 & 0 & 0 & 0 & & \\
\hline
\end{tabular}

In the table 2 we can notice a gradual decrease in the number of children with the asymmetric tonic neck reflex retained. In $13 \%$ of children aged 3 years there is a small reaction, and there is no complete presence of the reflex in any 3 years old child. A small reaction was observed in $5 \%$ of children aged 4 years, and there was not observed complete reaction. In all children in the group of 5 years the reflex was totally integrated, there was not even small reaction. There was noticed more prevalent reflex persistence in males than in females.

Table 2. Analysis of the appearance of Asymmetric tonic neck reflex

\begin{tabular}{|c|c|c|c|c|c|c|c|c|c|c|}
\hline \multirow[t]{2}{*}{ Reflex } & \multirow[t]{2}{*}{ Gender } & \multirow[t]{2}{*}{ Age } & \multicolumn{2}{|c|}{0} & \multicolumn{2}{|c|}{1} & \multicolumn{2}{|c|}{2} & \multicolumn{2}{|c|}{ Total } \\
\hline & & & $\mathrm{N}$ & $\%$ & $\mathrm{~N}$ & $\%$ & $\mathrm{~N}$ & $\%$ & $\begin{array}{l}\mathrm{N} /+ \\
\text { ans. }\end{array}$ & $\%$ \\
\hline & \multirow[b]{2}{*}{ Male } & 3 & 4 & 80 & 1 & 20 & 0 & 0 & \multirow[t]{2}{*}{2} & \multirow[t]{2}{*}{93.4} \\
\hline & & 4 & 10 & 91 & 1 & 9 & 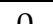 & 0 & & \\
\hline
\end{tabular}




\begin{tabular}{|l|l|c|c|c|c|c|c|c|c|c|}
\hline \multirow{2}{*}{ ATNR } & & 5 & 12 & 100 & 0 & 0 & 0 & 0 & & \\
\cline { 2 - 12 } & \multirow{3}{*}{ Female } & 3 & 9 & 90 & 1 & 10 & 0 & 0 & \multirow{2}{*}{1} & 3.4 \\
\cline { 3 - 13 } & 4 & 8 & 100 & 0 & 0 & 0 & 0 & & \\
\cline { 3 - 12 } & 5 & 11 & 100 & 0 & 0 & 0 & 0 & & \\
\hline
\end{tabular}

In the $3^{\text {rd }}$ table are present the results from the examination of the spinal gallant reflex. In the 3 years old males there was small reaction only in one respondent, and there was not complete reaction in any male. Both groups 4 and 5 years, had two respondents with small reactions, and there was not complete reflex presence. In the girls, respondents in 3 years old two had small reaction and one girl had persistence of the reflex. In 4 years old girls there was not any reflex reaction, and in the group of 5 years old, two $(18 \%)$ showed small reaction of the reflex stimulation.

Table 3. Analysis of the appearance of the Spinal gallant reflex

\begin{tabular}{|c|c|c|c|c|c|c|c|c|c|c|}
\hline \multirow[t]{2}{*}{ Reflex } & \multirow[t]{2}{*}{ Gender } & \multirow[t]{2}{*}{ Age } & \multicolumn{2}{|c|}{0} & \multicolumn{2}{|c|}{1} & \multicolumn{2}{|c|}{2} & \multicolumn{2}{|c|}{ Total } \\
\hline & & & $\mathrm{N}$ & $\%$ & $\mathrm{~N}$ & $\%$. & $\mathrm{N}$ & $\%$ & $\begin{array}{l}\mathrm{N} /+ \\
\text { ans. }\end{array}$ & $\%$ \\
\hline \multirow{6}{*}{$\begin{array}{l}\text { Spinal } \\
\text { gallant } \\
\text { reflex }\end{array}$} & \multirow{3}{*}{ Male } & 3 & 4 & 80 & 1 & 20 & 0 & 0 & \multirow[t]{3}{*}{5} & \multirow[t]{3}{*}{17.8} \\
\hline & & 4 & 9 & 82 & 2 & 18 & 0 & 0 & & \\
\hline & & 5 & 10 & 83 & 2 & 17 & 0 & 0 & & \\
\hline & \multirow{3}{*}{ Female } & 3 & 7 & 70 & 2 & 20 & 1 & 10 & \multirow[t]{3}{*}{5} & \multirow[t]{3}{*}{17.24} \\
\hline & & 4 & 8 & 100 & 0 & 0 & 0 & 0 & & \\
\hline & & 5 & 9 & 82 & 2 & 18 & 0 & 0 & & \\
\hline
\end{tabular}

Table 4. Analysis of the appearance of the Symmetric tonic neck reflex

\begin{tabular}{|c|c|c|c|c|c|c|c|c|c|c|}
\hline \multirow[t]{2}{*}{ Reflex } & \multirow[t]{2}{*}{ Gender } & \multirow[t]{2}{*}{ Age } & \multicolumn{2}{|c|}{0} & \multicolumn{2}{|c|}{1} & \multicolumn{2}{|c|}{2} & \multicolumn{2}{|c|}{ Total } \\
\hline & & & $\mathrm{N}$ & $\%$ & $\overline{\mathrm{N}}$ & $\%$ & $\mathrm{~N}$ & $\%$ & $\begin{array}{c}\mathrm{N} /+ \\
\text { ans. }\end{array}$ & $\%$ \\
\hline \multirow{6}{*}{ STNR } & \multirow{3}{*}{ Male } & 3 & 4 & 80 & 1 & 20 & 0 & 0 & \multirow[t]{3}{*}{4} & \multirow[t]{3}{*}{14.2} \\
\hline & & 4 & 10 & 91 & 1 & 9 & 0 & 0 & & \\
\hline & & 5 & 10 & 83 & 2 & 17 & 0 & 0 & & \\
\hline & \multirow{3}{*}{ Female } & 3 & 9 & 90 & 1 & 10 & 0 & 0 & \multirow[t]{3}{*}{2} & \multirow[t]{3}{*}{6.8} \\
\hline & & 4 & 8 & 100 & 0 & 0 & 0 & 0 & & \\
\hline & & 5 & 10 & 91 & 1 & 9 & 0 & 0 & & \\
\hline
\end{tabular}

The table number 4 presents the results from the examination of the symmetric tonic neck reflex. In the male groups of 3 and 4 year old there is one respondent in each group manifesting small reactions, and there was not 
observed complete reaction. In the group of 5 years old males $2(17 \%)$ had small reactions. In female respondents two girls, one in 3 years old and one in 5 years old, had small reflex reaction. In this reflex was also observed more frequent persistence in males than in females.

Gieysztor, Choińska, and Paprocka-Borowicz (2016) in their study "Persistence of the primitive reflexes and associated motor problems in healthy preschool children" have noticed that according the psychomotor abilities $9 \%$ of the children were in the category of "altered development", $29 \%$ in "delayed development", 59\% in "normal" and 3\% in "very good development". The greater the severity of the reflex, the motor efficiency was lower $(p<0.05)$. At the sample of 35 children aged 4-6 years old, most prevalent was asymmetric tonic neck reflex, in $66 \%$ of respondents, and at least prevalent was symmetric tonic neck reflex, in $34 \%$. Grzywniak in his research comparing normal school aged children, among which one group of children were orphans, has noticed that $55 \%$ of examinees have persistence of the primitive reflexes on the first or second level, or according our scoring they have small reactions.

\section{Conclusion}

Persistence of the primitive reflexes out of the normal time frame, even they present in traces are significant and affect normal psychomotor development of the child. If the staff know normal time frame of the reflexes and the impact they have on development of healthy children, not only would they have a faster reaction to their persistence, but they could also prevent subsequent disorders and consequences. 


\section{References}

Blomberg, H., M. Dempsey. (2011) Movements that Heal. UK: BookPal.

Fiorentino, R. M. (1980) Normal and abnormal development: the influence of primitive reflexes on motor development. Springfield Illinois, USA: Charles C Thomas publisher.

Gieysztor E. Z., Choińska A. M., and Paprocka-Borowicz Małgorzata (2016). Persistence of primitive reflexes and associated motor problems in healthy preschool children. Arch Med Sci. 2018 Jan; 14(1): 167-173. Published online 2016 Jun 13. doi: 10.5114/aoms.2016.60503.

Goddard, B. S. (2002). Reflexes, learning and behavior: A window into the child's mind. Oregon: Fern Ridge Press.

Goddard, B. S. (2014). Neuromotor Immaturity in Children and Adults The INPP Screening Test for Clinicians and Health Practitioners. Oxford: John Wiley \& Sons, Ltd.

Goddard, B. S. (2017). Attention, Balance and Coordination. UK: John Wiley \& Sons Ltd.

Grzywniak C. (2010). The effect of the form of persistent trace reflexes to rise the difficulties of school. Szkoła Specjalna. 2:98-112.

Integrated Learning Strategies. (2016). What is a Retained Spinal Galant and Why Does it Make my Child Wiggle and Squirm in the Classroom? [Cited march 2019], Available from URL: https://ilslearningcorner.com/2016-11-spinal-galant-retained-spinal-galant-make-child-wigglesquirm/.

Konicarova J., Bob P. (2012). Retained Primitive Reflexes and ADHD in Children. In Activitas Nervosa Superior 2012, 54, No. 3-4.

Iiyama M., Miyajima T., Hoshika A. (2002). Developmental change of Moro reflex studied with a three-dimensional motion analysis system. No To Hattatsu. 2002; 34(4):307-312.

Malina R. M., Bouchard C., Bar-Or O. (2004). Growth, maturation and physical activity. 2, Champaign, IL: Human Kinetics.

Mejashki-Boshnjak, V. (2008). Rani neuroloshki razvoj djeteta. PediatrCroat, 2008; 52(Supl 1), 36-42.

Payne, V. G., Isaacs D. L. (2012). Human motor development: A lifespan approach. Eighth edition. New York: McGraw-Hill.

Walker, S. (2013). Retained neonatal reflexes - a revolutionary approach to treating children with learning difficulties and behavioral problems. Sydney: Retained Neoanatal Reflexes RNR.

Чичевска-Јованова Н., Рашиќ-Цаневска О. (2013) Рана интервенцииа на деияа родени со фактор на ризик. Скопје: Филозофски факултет. 